\section{Members of the PbFCl-Type Family: Possible Candidates for Room-Temperature Photochemical Hole Burning}

\author{
Raivo Jaaniso $\left.\left.{ }^{a}\right)^{c}\right)$, Hans Hagemann ${ }^{a}$ ), Frank Kubel ${ }^{b}$ ), and Hans Bill $\left.{ }^{a}\right)^{*}$
}

Abstract. We report on crystal growth and about physico-chemical studies on $\mathrm{Sr}_{\mathrm{y}}$ $\mathrm{Ba}_{1-y} \mathrm{FCl}_{x} \mathrm{Br}_{1-x}(y=0,0.5$, and 1$)$ compounds doped with $\mathrm{Sm}$. Persistent spectral hole burning at $300 \mathrm{~K}$ is further reported on $\mathrm{Sr}_{0.5} \mathrm{Ba}_{0.5} \mathrm{FCl}_{0.5} \mathrm{Br}_{0.5}: \mathrm{Sm}$ single crystals.

\section{Introduction}

Recent successful photochemical hole burning experiments realized in our laboratory with $\mathrm{SrFCl}_{0.5} \mathrm{Br}_{0.5}: \mathrm{Sm}^{2+}$ crystals [1] at room temperature produced evidence of new useful properties of the $\mathrm{PbFCl}$ family.

Among the large number of members contained in this family, the alkaline-earth or rare-earth double halides MeFX with $\mathrm{Me}=\mathrm{Ca}, \mathrm{Sr}, \mathrm{Ba}, \mathrm{Eu}, \mathrm{Sm}$ etc. and $\mathrm{X}=\mathrm{Cl}, \mathrm{Br}, \mathrm{I}$ are of particular interest to us.

These compounds have since as far as 1894 been the subject of crystallochemical studies [2]. They all crystallize in the tetragonal $P 4 / \mathrm{nmm}$ (no 129) Matlockit structure $D_{4}^{7}($ Fig. I). Crystallographic data including all coordinates of the atoms in the unit cell are now available for most of them [3].

It is further known for some time already that mixed crystals can be grown from equimolar mixtures of $\mathrm{SrFCl}$ and $\mathrm{SrFBr}$ and also of $\mathrm{BaFCl}$ and $\mathrm{BaFBr}$. From our EPR experiments performed on $\mathrm{Gd}^{3+}$ doped mixed crystals of this composition, we concluded that neither the chloride nor the bromide enters into a fluoride lattice position [4]. Instead, they are located in

\footnotetext{
*Correspondence: Prof. H. Billia)

a) Département de Chimie Physique

Université de Genève

30, quai Ernest-Ansermet

$\mathrm{CH}-1211$ Genève 4

b) Département de Chimie Minérale,

Analytique et Appliquée

Université de Genève

30, quai Ernest-Ansermet

$\mathrm{CH}-1211$ Genève 4

c) Institute of Physics

Estonian Academy of Sciences

Riia Street 142

Tartu 202400, Estonia
}

the double halogen layers between the $\mathrm{Me}-\mathrm{F}-\mathrm{Me}$ sheets. In other words, part of the basic structure is unaffected by the mixing process in these systems.

Recent systematic crystallochemical studies of the miscibility range give for several mixtures the phase diagrams and global crystal structure [5], when applicable.

In particular, it is known now [5a, b] that $\mathrm{SrFCl}_{x} \mathrm{Br}_{1-x}$ and $\mathrm{BaFCl}_{x} \mathrm{Br}_{1-x}$ exist and are miscible for all values of $x$ between 0 and 1 .

According to [5a], a tetragonal structure persists through this range of $x$ values, and the lattice parameters $a$ and $c$ are given by $a=421.8-9.2 x[\mathrm{pm}]$ and $c=733.7-$ $37.9 x[\mathrm{pm}]$ for $\mathrm{SrFCl}_{x} \mathrm{Br}_{1-x}$, and $a=450.8$ $11.4 x[\mathrm{pm}]$ and $c=741.1-18.6 x[\mathrm{pm}]$ for $\mathrm{Ba} \mathrm{FCl} \mathrm{Br}_{1-x}$.
All of the rare earth ions are easily dissolved into these compounds at an impurity concentration level. This is in particular true for the MeFX subset which will be considered in the following $(\mathrm{Me}=\mathrm{Sr}, \mathrm{Ba})$.

The burning of persistent spectral holes into the inhomogeneously broadened impurity bands is now widely used in the low-temperature high-resolution optical studies [6]. The need to use liquid $\mathrm{He}$ temperatures in hole burning experiments (as a rule) is caused by the broadening (and weakening) of the impurity zero phonon lines and by the decrease in stability of the product states with increasing temperature.

The main potential applications of the spectral hole-burning method allow to increase considerably the density of opticaldata storage [6] or to increase the parallelism of processing [7]. This is made possible by the introduction of the spectral dimension in addition to the spatial coordinates. For this reason, there is an increasing interest to find materials which can be utilized at higher temperatures.

In the $\mathrm{PbFCl}$ family, hole-burning experiments were performed first on the ordered systems $\mathrm{BaFCl}: \mathrm{Sm}^{2+}[8 \mathrm{a}]$ and in $\mathrm{CaFCl}: \mathrm{Sm}^{2+}[8 \mathrm{~b}]$. Part of the $\mathrm{BaFCl}$ crystals (class I in [8a]), showed that spectral holes, burnt at $2 \mathrm{~K}$, survived partly after cycling to room temperature and back again to $2 \mathrm{~K}$.

Hole burning above liquid $\mathrm{N}_{2}$ temperature (at $80 \mathrm{~K}$ ) was first reported on a polymer matrix, doped with a derivative of the porphyrine molecule [9]. Although several other molecular systems have been studied now at 80-90 K [10], the extrapolation of these results to room temperature

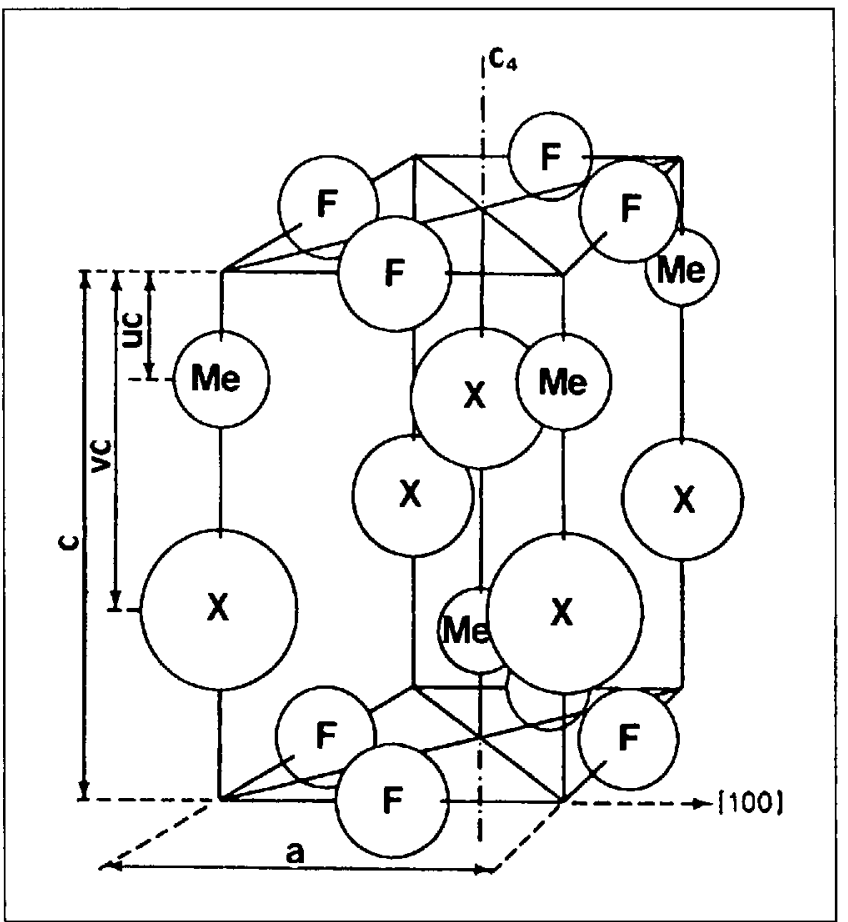
and $X=C l, B r, I$ 
shows that the zero phonon lines become considerably weaker, and their (homogeneous) widths achieve the width of the inhomogeneous distribution ( $>100 \mathrm{~cm}^{-1}$ ). In 1989 , results at $77 \mathrm{~K}$ were published for the Sm-doped powders of the composition $\mathrm{BaFCl}_{0.5} \mathrm{Br}_{0.5}[\mathrm{I} 1]$, where substitutional disorder induces considerable additional inhomogeneous broadening (see also [12] [13]). More detailed hole-burning studies on this compound are published in [14][15]

This investigation was, in part, motivated by the disparity in the experimental data. As already pointed out in [8a], crystals of nominally the same composition give different results. Further, our $\mathrm{BaFCl}_{0.5} \mathrm{Br}_{0.5}: \mathrm{Sm}^{2+}$ crystal spectra do not agree with those published for powders of the same nominal composition prepared under different conditions [11][13][14].

This paper succintly presents information about sample preparation and reports the results obtained of an EPR, X-ray, Raman, luminescence and hole-burning study of $\mathrm{Sr}_{y} \mathrm{Ba}_{1-y} \mathrm{FCl}_{x} \mathrm{Br}_{1-x}(y=0,0.5,1)$.

\section{Structure and Crystal Growth}

As is easily verified in Fig. 1, the MeFX structure consists of $\left(\mathrm{Me}_{4} \mathrm{~F}\right)^{n+}$ tetrahedra which form sheets reminiscent of a truncated $\mathrm{CaF}_{2}$ structure (perpendicular to the $C_{4}$ axis). Between these sheets, which are separated by one lattice spacing, are sandwiched the double layers of $\mathrm{X}^{-}$anions. The two layers are mutually shifted by $1 / 2[110]$. The thickness of the $\left(\mathrm{Me}_{4} \mathrm{~F}\right)^{n+}$ sheets is almost independent of $\mathrm{X}$ for a given metal, and the $\mathrm{Me}-\mathrm{F}$ bond lengths are always very close to the sum of the two ionic radii.

The two metal sites of the unit cell have $C_{4 v}$ symmetry. They are related by the inversion operation of the factor group of this non-symmorphic space group.

Crystals were grown either in a Bridgman furnace or in a Kyropoulos-Czrochralski setup. The following points are worth of note. Both apparatus are built in such a way that the crystals can be grown either in an atmosphere of ultrapure Ar or under high vacuum. We always doped our crystals with rare-earth fluoride of at least $3 \mathrm{~N}$ purity (in particular $\mathrm{SmF}_{3}$ ). In an unpublished study [16], we have systematically hydrolized (typically $8 \mathrm{~h}, 15 \mathrm{~mm} \mathrm{Hg}$ $\mathrm{H}_{2} \mathrm{O}$ vapor) pure $\mathrm{SrFCl}$ crystals and subsequently $X$-rayed them. EPR results obtained at $4.2-\mathrm{K}$ sample temperature for these crystals allowed to identify an $\mathrm{O}_{2}$ molecular ion which substitutes for a $\mathrm{F}^{-}$ ion. Its $\mathrm{g}$ values are:

$\mathrm{g}_{[/ 10 \mid}=2.1719, \mathrm{~g}_{\mid / 10]}=2.005, \mathrm{~g}_{\mid 00 /]}=2.06$.

These experimental results were useful in applying EPR as an analytical tool for these substances.
The second point concerns the shape of the crucibles, in particular with repect to the Bridgman technique. We always observed that the crystals grew much faster, when their $c$ axis is parallel to the solidification isotherm. The reason for this behavior is very likely related to configurational entropy inside a macroscopically small volume comprising the crystallized surface and a thin layer of the melt.

In the event where the growth interface is perpendicular to the $c$ axis, then within a given short time interval a metal plane (for instance) has to be formed, needing the preferential presence of metal ions in the volume. This processus is statistically rather improbable, because the configurational entropy would have to be drastically reduced within the small volume. Near equilibrium, this volume normally contains similar amounts of metal, fluoride, and halogen ions, which will adhere to the crystal with similar probability during solidification. Growth prependicular to the $c$ axis is thus much more favorable, and in agreement with a local maximum configurational entropy.

We developed for this reason crucibles of rectangular cross-section which allow to grow even in our Brigman furnace useable single crystals, in spite of this extremely anisotropic growth pattern.

The mixed compounds $\mathrm{SrFCl}_{x} \mathrm{Br}_{1-x}: \mathrm{Sm}$ used in the Raman and X-ray powder study were prepared in graphite boats placed in a sealed quartz ampoule. After introduction of the compound, the ampoule was outgassed at $150-200^{\circ}$, then, $0.2 \mathrm{~atm}$ of ultrapure Ar was admitted. Synthesis of the mixed compounds was achieved by melting the mixture of $\mathrm{SrFCl}$ and $\mathrm{SrFBr}$ at $1100^{\circ}$, and cooling succesively to 1000,900 , and $850^{\circ}$ before switching the furnace off.

\section{Spectroscopic Results}

\section{$E P R$}

An early study in 1972 [16] of $\mathrm{Gd}^{3+}$ in $\mathrm{SrFC}_{0.5} \mathrm{Br}_{0.5}$ allowed to identify, in addition to an axial $\mathrm{Gd}^{3+}$ EPR spectrum, the signals of a monoclinic variety together with many additional lines.

A systematic EPR study was realized on the pure hosts $\mathrm{MeFCl}$ and $\mathrm{MeFBr}$ ( $\mathrm{Me}=\mathrm{Ca}, \mathrm{Sr}, \mathrm{Ba}$ ) doped with $\mathrm{Gd}^{3+}$ and $\mathrm{Eu}^{2+}$, respectively. The spectra observed for these systems were always of axial symmetry. The second-order crystal field term was analyzed [17] with the aid of an angular overlap model. This approach, though approximate, allowed to show that the axial $\mathrm{X}^{-}$ion and the four other $\mathrm{X}^{-}$ions mutually act oppositely onto the ground state [17]. The effect of the fluoride neigh- bors is remarkably weak. This fact explains qualitatively the very large variations of the $b_{2}{ }^{0}$ crystal field parameter of the ground state multiplet as a function of the nature of $X$ for a given cation [18]

These results permitted to identify the axial $\mathrm{Gd}^{3+}$ signal in $\mathrm{SrFCl}_{0.5} \mathrm{Br}_{0.5}$ as arising from an intact $\mathrm{Cl}^{-}$neighborhood, whereas the monoclinic spectrum is probably due to the replacement of one $\mathrm{Cl}^{-}$ neighbor by a $\mathrm{Br}^{-}$ion. Work is not yet finished

\section{X-Ray Study}

Our powder diffraction measurements on $\mathrm{SrFCl}_{x} \mathrm{Br}_{1-r}: \mathrm{Sm}(0.1 \%)$ confirm [5a] the linear variation, with respect to $x$, of the tetragonal lattice parameters. There are additional weak lines on our GuinierHägg photographs. They are of two types. Some lines are consistent with the presence of $\mathrm{SrF}_{2}$ in the samples. Four additional lines are seen between $\theta=7^{\circ}$ and $\theta=11^{\circ}$; their position varies with the mole fraction $x$.

Two single crystals were further studied: $\mathrm{SrFCl}_{0.5} \mathrm{Br}_{0.5}: \mathrm{Sm}(\mathrm{A})$ and an undoped $\mathrm{SrFCl}_{0.5} \mathrm{Br}_{0.5}$ (B). Both presented on long exposure precession photographs and from diffractometer measurements (sample A only) an additional tetragonal lattice with $a=814.49(36) \mathrm{pm}$ and $c=697.43(39) \mathrm{pm}$ with the same orientation as the parent structure. The normal lattice parameters of these crystals are $a=416.08(7) \mathrm{pm}$ and $c=713.2(2) \mathrm{pm}$. Subsequent polishing of the surfaces of the pure sample B did not eliminate completely this additional lattice. At present, two hypotheses have to be considered.

Either the extra structure arises from epitaxial layers of $\mathrm{SrCl}_{2-y} \mathrm{Br}_{y}$ which are intercalated. The simultanous presence of the $\mathrm{SrF}_{2}$ lines suggest indeed minor partial decomposition of the mixed fluorohalide. Raman spectra of a powdered sample of $\mathrm{SrFC1}_{0.5} \mathrm{Br}_{0.5}: \mathrm{Sm}$ which has been subjected to 4-h exposure to $\mathrm{X}$-rays were identical to those of a virgin sample.

The other less likely hypothesis is that our crystals present an 'out of step' incommensurate phase. We were not yet able to observe the postulated $\mathrm{SrCl}_{2-y} \mathrm{Br}_{4}$ phase spectroscopically. Note that an epitaxial layer needs not to have the same orientation and symmetry as the substrate.

\section{Raman Results}

1. Powder Spectra of the Solid Solutions $\mathrm{SrFCl}_{\mathrm{x}} \mathrm{Br}_{I-\mathrm{x}}$ doped with $0.1 \%$ Samarium

Fig. 2 shows that the spectra change continuously with $x$ varying form 0 to 1 . No additional lines appear and no lines disappear (with the exception of the $E_{\mathrm{g}}$ 
mode around $100 \mathrm{~cm}^{-1}$ at intermediate compositions), indicating that the crystal structure is similar for all. Table 1 collects the Raman shifts observed at $300 \mathrm{~K}$. The two high-frequency bands around 240 and $280 \mathrm{~cm}^{-1}$ have been assigned to mainly fluoride vibrations [19a]. Indeed, the width of these bands is not increased significantly in the mixed compounds, while the lowest frequency bands broaden considerably even for $x=0.1$ or $x=0.9$.

A plot of the observed Raman shifts vs. composition yields that the frequency of the two fluoride modes varies linearly with $x$. It has been suggested previously [18] that these frequencies should depend on the lattice parameter $a$. Indeed, the Xray data show a linear variation of both

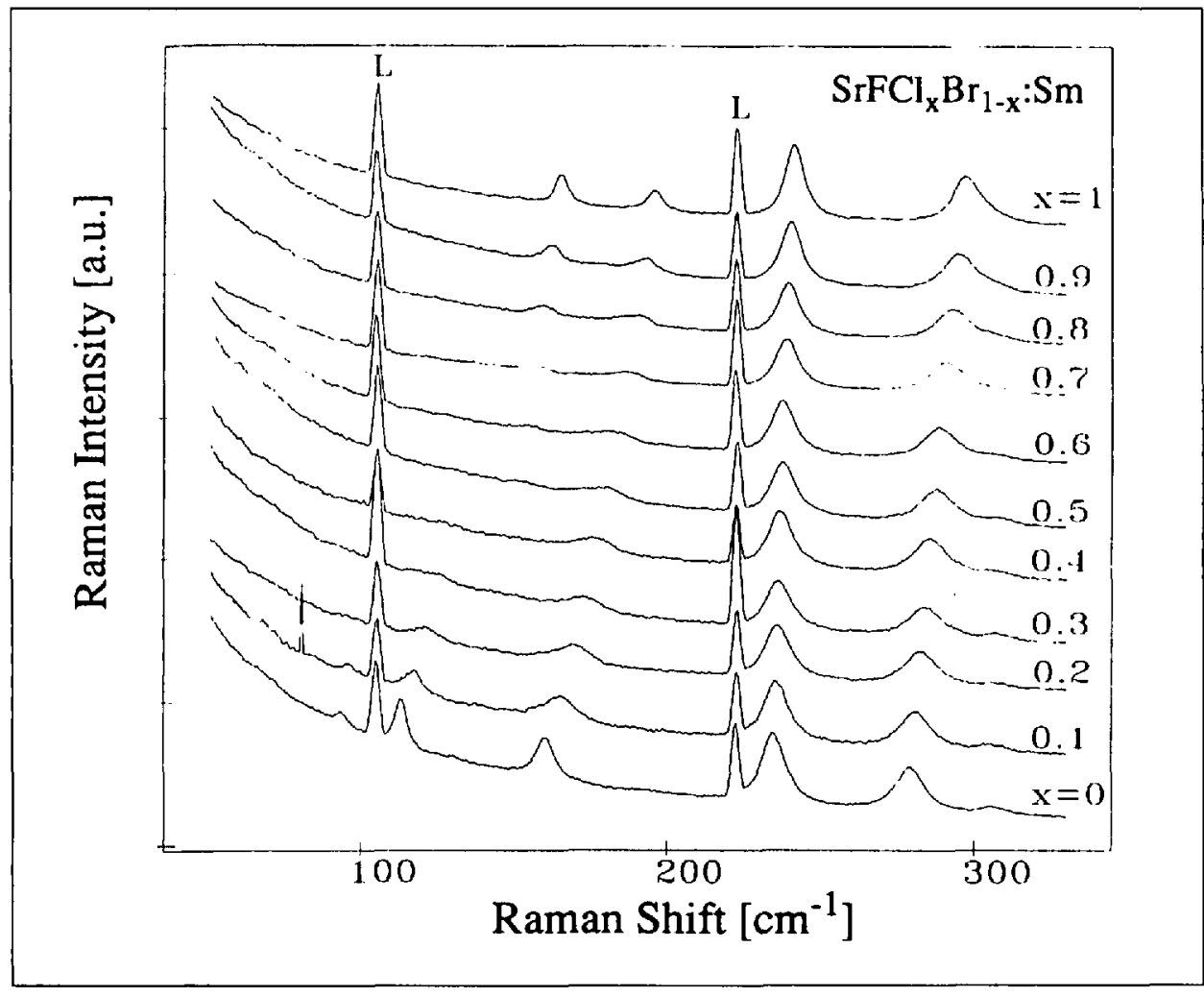

Fig. 2. Raman spectra at $300 \mathrm{~K}$ of powdered $\mathrm{SrFCl}_{\mathrm{x}} \mathrm{Br}_{1-\mathrm{x}}: 0.1 \% \mathrm{Sm}$. The sharp lines noted $\mathrm{L}$ are laser plasma lines. Slit width $200 \mu$, laser power $c a$. $100 \mathrm{~mW}$.

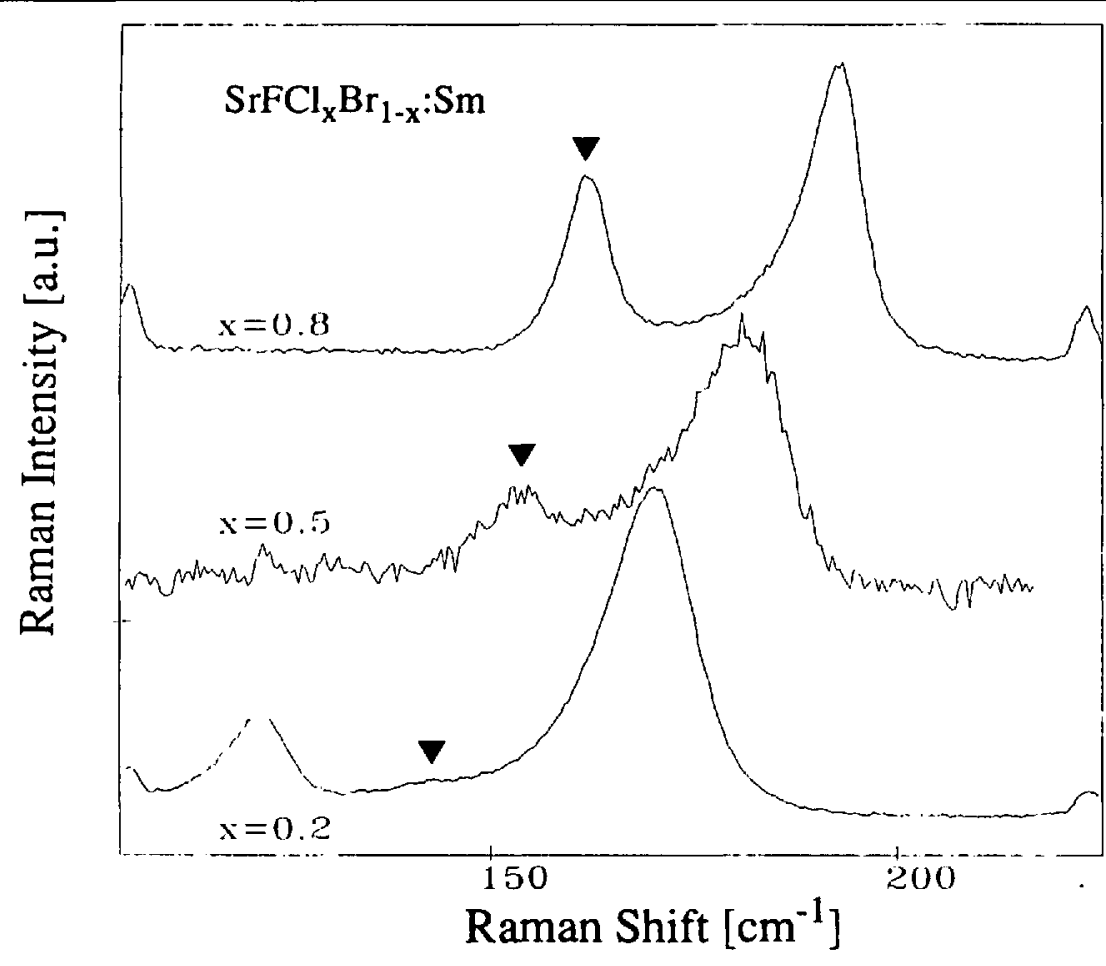

Fig. 3. (cc)+(ca) polarized Raman spectra of crystals $\mathrm{SrFCl}_{\mathrm{x}} \mathrm{Br}_{1-\mathrm{x}}$ lattice parameters with $x$. One may thus use the position of the highest frequency Raman bands to confirm the composition of the compound prepared.

This property is illustrated for the crystal $\mathrm{BaFCl}_{0.5} \mathrm{Br}_{0.5}: \mathrm{Sm}$. The lattice parameters of the system $\mathrm{BaFCl} \mathrm{Br}_{1-x}$ are also reported [5a] to vary linearly with $x$. The highest frequency Raman band is predicted to be at $0.5 x(251+238)=244.5 \mathrm{~cm}^{-1}$ and observed at $245 \mathrm{~cm}^{-1}$. Our X-ray powder diffraction data yield the parameters $a$ $=444 \mathrm{pm}$ and $c=732 \mathrm{pm}$; these values are indeed close to the middle of the corresponding values for $\mathrm{BaFCl}$ and $\mathrm{BaFBr}$.

\section{Single-Crystal Measurements}

Fig. 3 compares the spectra of three samples between 110 and $220 \mathrm{~cm}^{-1}$. The two strongest bands of the $x=0.8$ sample at 160 and $191 \mathrm{~cm}^{-1}$ correlate with the mainly $\mathrm{Sr}-\mathrm{Cl}(\mathrm{Sr}-\mathrm{Br}$, respectively) stretching vibrations of the respective pure compounds [19]. In the mixed crystals, an important frequency shift of these bands is observed, as well as a varying and asymmetric line shape. An elementary sitegroup analysis of the mixed crystals obviously seems thus not to be adequate. It is further interesting to note the significant change of the relative intensity of the $E_{\mathrm{g}}$ mode (labelled in Fig. 3). Furthermore, a spectrum of a crystal with $x=0.5$ was obtained at $77 \mathrm{~K}$. The linewidth of the fluoride modes (above $200 \mathrm{~cm}^{-1}$ ) decreased significantly, while the bands at 153 and $180 \mathrm{~cm}^{-1}$ retained essentially their room temperature width and shape.

Another spectrum of a crystal which had been pulled from the melt, with nominal composition $\mathrm{SrF}_{1 / 3} \mathrm{Cl}_{1 / 3} \mathrm{Br}_{1 / 3}$ : $\mathrm{Sm}$, yielded the same spectrum as the crystal $\mathrm{SrFCl}_{0.5} \mathrm{Br}_{0.5}: \mathrm{Sm}$. This observation, in conjunction with identical Sm luminescence spectra for both crystals, confirms the stabilizing role of the fluoride to form the MeFX compounds: the chloride or bromide ions do not substitute in the fluoride layers. Note that in this case the nominal composition does not correspond to the real one.

The polarized spectra of $\mathrm{Sr}_{0.5} \mathrm{Ba}_{0.5}$ $\mathrm{FCl}_{0.5} \mathrm{Br}_{0.5}$ are quite similar to those of $\mathrm{BaFCl}_{0.5} \mathrm{Br}_{0.5}$ and $\mathrm{SrFCl}_{0.5} \mathrm{Br}_{0.5}$. The observed Raman shifts are collected in Table 1. Those for the $\mathrm{Ba}_{0.5} \mathrm{Sr}_{0.5}$ crystal fall between those of the $\mathrm{Ba}$ and $\mathrm{Sr}$ crystals. These similarities tend to show that the general structure of $\mathrm{Ba}_{0.5} \mathrm{Sr}_{0.5} \mathrm{FCl}_{0.5} \mathrm{Br}_{0.5}$ is also tetragonal or deviates only slightly from this symmetry. No line splittings or additional lines are observed in these spectra, whereas an X-ray study [5b] of mixed compounds of the type ( $\mathrm{SrFCl}-\mathrm{BaFCl}$ ) shows that there is a small monoclinic 
deviation for some compositions. Thus, Raman spectroscopy seems in this situation not powerful enough to decide between the possible symmetries.

\section{Hole-Burning Experiments}

Persistent hole burning was first observed at room temperature in $\mathrm{SrFCl}_{0.5} \mathrm{Br}_{0.5}: \mathrm{Sm}^{2+}$ mixed crystals [1]. Two transitions, ${ }^{5} \mathrm{D}_{1}-{ }^{7} \mathrm{~F}_{0}$ and ${ }^{5} \mathrm{D}_{0}-{ }^{7} \mathrm{~F}_{0}$ of $\mathrm{Sm}^{2+}$, were studied and the homogeneous linewidths, $\Gamma_{h}$, equal to 1.75 and $1.3 \mathrm{~cm}^{-1}$, respectively, were determined for these transitions. The $\mathrm{Br}-\mathrm{Cl}$ disorder increases the inhomogeneous linewidth by a factor of $10^{2}$ with respect to the $\mathrm{SrFCl}$ lattice (previously also observed for the $\mathrm{BaFCl}_{0.5} \mathrm{Br}_{0.5}$ system [11]). This disorder

does not, however, affect the values of $\Gamma_{h}$ in $\mathrm{SrFC1}_{0.5} \mathrm{Br}_{0.5}: \mathrm{Sm}^{2+}$ at room temperature. The hole-burning mechanism was found to be two-photon photoionization of $\mathrm{Sm}^{2+}$ followed by electron trapping, as already observed in $\mathrm{BaFCl}: \mathrm{Sm}^{2+}$ [8a].

Here, we report our preliminary results for the $\mathrm{Sr}_{0.5} \mathrm{Ba}_{0.5} \mathrm{FCl}_{0.5} \mathrm{Br}_{0.5}$ single crystal host. Fig. 4 illustrates the hole burning in the ${ }^{5} \mathrm{D}_{1}-{ }^{7} \mathrm{~F}_{0}$ transition. The fluorescence excitation spectra were measured by scanning the wavelength of a tunable dye laser (DCM dye, 0.15- $\mathrm{cm}^{-1}$ linewidth) and recording the nonresonant fluorescence via a color filter (RG9).

Hole burning occurred under conditions similar to those for $\mathrm{SrFC}_{0.5} \mathrm{Br}_{0.5}: i$ ) pre-irradiation of the sample in an intense $\mathrm{Ar}^{+}$laser beam was needed to produce deeper holes; ii) a 50-mW laser beam,

Table I. Room-Temperature Raman Shifts $\left[\mathrm{cm}^{-1}\right]$

$\begin{array}{lllllll}\mathrm{SrFCl}[18][19 \mathrm{a}] & 107 & 155 & 165 & 195 & 241 & 296 \\ \mathrm{SrFCl}_{0.8} \mathrm{Br}_{0.2} & & & 160 & 191 & 240 & 294 \\ \mathrm{SrFCl}_{0.5} \mathrm{Br}_{0.5} & & 131 & 153 & 180 & 236 & 287 \\ \mathrm{SrFCl}_{0.8} \mathrm{Br}_{0.2} & 97 & 121 & 142 & 169 & 235 & 282 \\ \mathrm{SrFBr}[19 \mathrm{~b}] & 94 & 113 & 130 & 160 & 234 & 278 \\ \mathrm{Sr}_{0.5} \mathrm{Ba}_{0.5} \mathrm{FCl}_{0.5} \mathrm{Br}_{0.5} & 79 & 122 & 146 & 162 & 222 & 263 \\ \mathrm{BaFCl}_{[18][19 \mathrm{a}]} & 82 & 132 & 143 & 165 & 216 & 251 \\ \mathrm{BaFCl}_{0.5} \mathrm{Br}_{0.5} & 79 & 115 & 135 & 151 & 215 & 245 \\ \mathrm{BaFBr}^{18}[18][19 \mathrm{a}] & 76 & 103 & 109 & 123 & 211 & 238\end{array}$

Fig. 4. $\mathrm{Sr}_{0.5} \mathrm{Ba}_{0.5} \mathrm{FCl}_{0.5} \mathrm{Br}_{0.5}$ : $\mathrm{Sm}^{2+}{ }^{5} D_{I^{-}}-7 F_{0}$ transition excitation spectrum (1) and the spectral hole (2). The hole is obtained as the difference between the initial spectrum and the spectrum, measured after 100 -s exposure with monochromatic light at $15867.4 \mathrm{~cm}^{-1}$. Spectrum (2) is shown with $8 x$ magnification and with the zero level at the dotted line. Top-model spectrum of the ${ }^{5} \mathrm{D}_{1}-{ }^{7} \mathrm{~F}_{0}$ transition with $\Gamma_{h}=3.5 \mathrm{~cm}^{-1}$ and $\Gamma_{\text {ih }}=35$ $\mathrm{cm}^{-1}$.
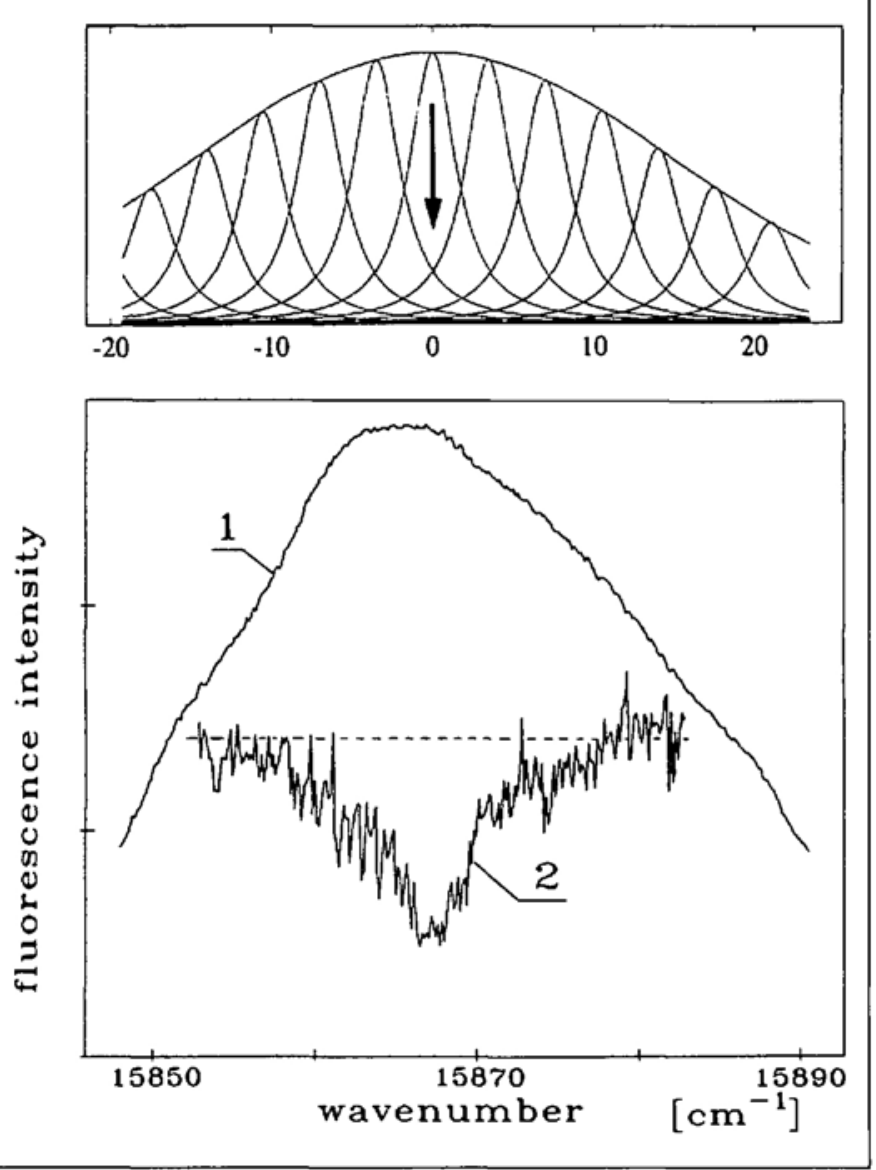

focussed to a diameter of $50-100 \mu \mathrm{m}$ on the sample, was used, with exposition times ranging from 10 to $100 \mathrm{~s}$ (for more details, see [1]).

The holes were fitted with a Lorentzian curve and the minimum holewidth, $\Gamma_{\text {hole }}$, was determined to be $7 \mathrm{~cm}^{-1}$. Using the simple relation $\Gamma_{\text {hole }}=2 \Gamma_{h}$, valid for shallow holes [6], one obtains that the value of $\Gamma_{h}$ is two times bigger than that determined for the same transition in $\mathrm{SrFCl}_{0.5} \mathrm{Br}_{0.5}$. We note a similar trend for ordered hosts: the room temperature value of $\Gamma_{h}$ in $\mathrm{BaFCl}$ is ca. 1.5 times the width in $\mathrm{SrFCl}$ (see Fig. 5).

To illustrate the occurrence of hole burning, a simple model spectrum consisting of the distribution of frequency-shifted homogeneous zero phonon lines is presented on the top of Fig. 4. Monochromatic irradiation (shown by the arrow) will excite strongly the resonant impurity ions, while the others, with shifted positions of their homogeneous lines, will experience considerably weaker excitation. As a result, mainly the resonant impurities will be photo-ionized (with a certain probability), leaving a hole in the inhomogeneous spectrum of $\mathrm{Sm}^{2+}$.

Fig. 5 presents the ${ }^{5} \mathrm{D}_{1}-{ }^{7} \mathrm{~F}_{0}$ transition fluorescence spectra for three mixed compounds, $\mathrm{Sr}_{y} \mathrm{Ba}_{1-y} \mathrm{FCl}_{0.5} \mathrm{Br}_{0.5}: \mathrm{Sm}^{2+} y=0$, $0.5,1)$, measured at room temperature Table 2 collects spectral data at room temperature for the ${ }^{5} D_{1}-{ }^{7} F_{0}$ and the ${ }^{5} D_{0}-$ ${ }^{7} \mathrm{~F}_{0}$ transitions. The fluorescence was excited via the broad $\mathrm{f}-\mathrm{d}$ transitions at $\mathbf{4 7 6 . 5}$ $\mathrm{nm}$ and, hence, includes the whole inhomogeneous ensemble.

The two maxima for the pure $\operatorname{Sr}(y=1)$ compound (spectrum l) may be associated with the different nearest neighbor $(\mathrm{Cl}, \mathrm{Br})$ ligand configurations [12a][13]. The $\mathrm{Ba}, \mathrm{Sr}$ mixed compound $(y=0.5$ ) shows a nearly Gaussian spectrum (spectrum 2), an indication of the increased influence of the next configuration sphere(s). The spectrum of the $\mathrm{Ba}(y=0)$ crystal (spectrum 3 ) is somewhat special, because it has less than half the width of the spectra described in the previous paragraph. More exactly, it consists of the main band and a weak shoulder (less than $10 \%$ of the total intensity), shifted by $c a$. $15 \mathrm{~cm}^{-1}$ to the higher frequency side. One may assume that in the $\mathrm{Ba}$ compound the $\mathrm{Sm}^{2+}$ preferably stabilizes in one type of the nearest neighbor configuration, whereas for the $\mathrm{Sr}$ compound the probabillities to occupy different configurations are more close. This difference may well be related to the cation sizes: the $\mathrm{Sr}^{2+}$ radius is practically the same as of $\mathrm{Sm}^{2+}$, whereas divalent $\mathrm{Ba}$ is about $13 \%$ bigger. The fact, that the impurity ions in the substitutionally mixed ionic crystals do not occupy the 
different ligand configurations with equal probabilities, is known, for example, from the studies of $\mathrm{Tl}^{+}$in mixed potassium halides [20] (see also the EPR results above). We note, in addition, that the shape of the spectrum did not depend on the excitation wavelength in the range of 458 $514.5 \mathrm{~nm}$, and that the polycrystalline samples (taken from the bottom of the crucible in the Czrochralski furnace, i.e. made simply by cooling down the melt) showed exactly the same spectra.

The room temperature spectra of $\mathrm{Sm}^{2+}$ in the matrices $\mathrm{SrFCl}, \mathrm{SrFBr}$, and $\mathrm{BaFCl}$ are shown at the top of Fig. 5 in order to present the correspondence with these systems. These $\mathrm{Sm}^{2+}$ lines are practically homogeneous, and the Lorentzian fit yielded the following values for their widths: $2.07(\mathrm{SrFCl}), 2.38(\mathrm{SrFBr})$, and $3.08 \mathrm{~cm}^{-1}$ $(\mathrm{BaFCl})$. We estimate the contribution from $\Gamma_{i h}$ and from instrumental width $(0.16$ $\mathrm{cm}^{-1}$ ) to be $10-20 \%$ of these values.

\section{Conclusion}

We have presented a multitude of physico-chemical properties of several members of the family of the title compound. The underlying investigations were motivated by fundamental research issues, but also undertaken in view of the possibility to use these materials for hole burning experiments at elevated temperatures. We have demonstrated the room temperature hole burning in two single crystal materials. The experiments were performed on well-defined and well-characterized samples. We believe that these results induce compelling necessity to continue a full range investigation of intermediate compounds of this family.

Recently, room temperature hole burning was communicated on $\mathrm{Mg}_{0.5} \mathrm{Sr}_{0.5}$ $\mathrm{FCl}_{0.5} \mathrm{Br}_{0.5}: \mathrm{Sm}^{2+}[21]$. This compound could be interesting for (co-)doping with transition metal impurities, which may more easily substitute for the smaller $\mathrm{Mg}^{2+}$ ions. Thereby, it would be useful to extend the comprehensive characterization of the present work to $\mathrm{Mg}$-containing compounds. Their nominal composition should be carefully verified, especially due to the fact that the $\mathrm{MgF}_{2}-\mathrm{MgCl}_{2}$ system is shown [22] to form only separate phases (i.e. no $\mathrm{MgFCl}$ can be made).

This work has been supported by the Swiss National Science Foundation.

Received: January 27, 1992

[1] R. Jaaniso, H. Bill, Europhys. Lett. 1991, 16,569 .

Table 2. Room-Temperature Fluorescence Spectra of $\mathrm{Sm}^{2+}$ in Mixed Crystals: Position at Maximum Intensity and Full Width at Half Maximum $\left[\mathrm{cm}^{-1}\right]$

\begin{tabular}{|c|c|c|c|c|}
\hline & $\begin{array}{l}{ }^{5} \mathrm{D}_{0}-{ }^{7} \mathrm{~F}_{0} \\
\text { Position }\end{array}$ & Width & $\begin{array}{l}{ }^{5} \mathrm{D}_{1-}{ }^{7} \mathrm{~F}_{0} \\
\text { Position }\end{array}$ & Width \\
\hline $\mathrm{SrFCl}_{0.5} \mathrm{Br}_{0.5}$ & 14492 & 30 & 15827 & 34 \\
\hline $\mathrm{Sr}_{0.5} \mathrm{Ba}_{0.5} \mathrm{FCl}_{0.5} \mathrm{Br}_{0.5}$ & 14526 & 30 & 15866 & 34 \\
\hline $\mathrm{Ba}_{0.5} \mathrm{FCl}_{0.5} \mathrm{Br}_{0.5}$ & 14540 & 12 & 15883 & 13 \\
\hline
\end{tabular}

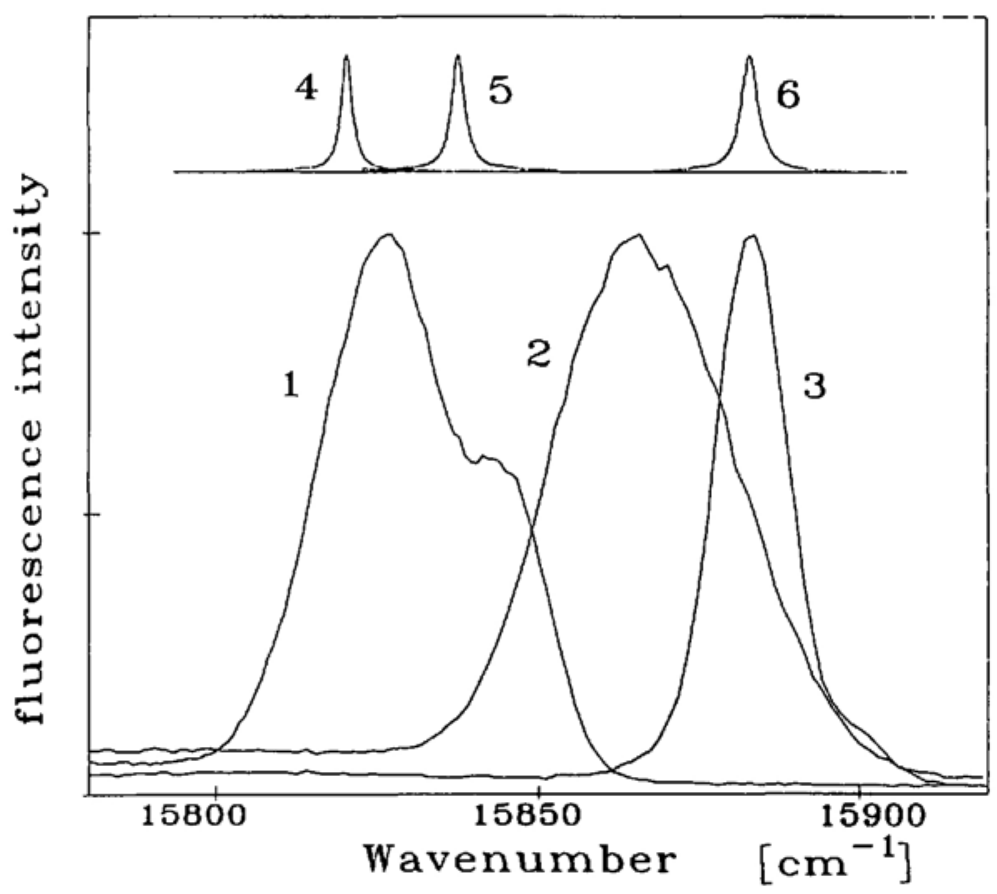

Fig. 5. ${ }^{5} \mathrm{D}_{1}-^{7} \mathrm{~F}_{0}$ transitionfluorescence spectraof $\mathrm{Sm}^{2+}$ at $300 \mathrm{~K}$ in $\mathrm{SrFCI} \mathrm{I}_{0.5} \mathrm{Br}_{0.5}(\mathrm{I}), \mathrm{Sr}_{0.5} \mathrm{Ba}_{0.5} \mathrm{FCl}_{0.5} \mathrm{Br}_{0.5}$ (2), $\mathrm{BaFCl}_{0.5} \mathrm{Br}_{0.5}$ (3), $\mathrm{SrFCl}(4), \mathrm{SrFBr}(5)$, and $\mathrm{BaFCl}(6)$

[2] C. Poulenc, Ann. Chim. Phys. 1894, 73, 2128.

[3] a) M. Sauvage, Acta Crystallogr., Sect. B 1974, 30, 2786; b) B.W. Liebich, D. Nicollin, ibid. 1977, 33, 2790; c) E. Niklaus, F. Fischer, J. Cryst. Growth 1972, 12, 337; d) H.B. Beck, Z Anorg. Allg. Chem. 1979, 451, 73.

[4] H. Bill, University of Geneva, unpublished results 1969.

[5] a) Lin Jianhua, Su Mianzeng, Gaodeng Xuexiao Huaxue Xuebao 1985, 6, 957; b) S.A. Hodorowicz, E. Hodorowicz, H.A. Eick, J. Solid State Chem. 1983, 50,180; c) Cryst. Res. Technol. 1984, 19, 1377; d) H.P. Beck, J. Solid. State Chem. 1978, 23, 213.

[6] W.E. Moerner, Ed., 'Persistent Spectral Hole-Burning: Science and Applications', 'Topics in Current Physics', Springer Verlag, Berlin, 1988, Vol. 44.

[7] U.P. Wild, A. Renn, C. De Caro, S. Bernet, Appl. Optics 1990, 29, 4329.

[8] a) A. Winnacker, R.M. Shelby, R.M. MacFarlane, Opt. Lett. 1985, 10, 350; b) A. Oppenlander, J.-C. Vial, R.M. MacFarlane, J.-P. Chaminade, J. Lumin. 1989, 42, 331.

[9] K. Sakoda, K. Kominami, M. Iwamoto, Jpn. J. Appl. Phys. 1988, 27, L-1304.

[10] a) W.P. Ambrose, W.E. Moerner, Chem.
Phys. 1990, 144, 71; b) A. Furusawa, K. Horie, J. Chem. Phys. 1991, 94, 80.

[11] C. Wei, S. Huang, J. Yu, J. Lumin. 1989, $43,161$.

[12] a) R. Baumert, J. Pelzl, S. Hüfner, Solid State Commun. 1975, 16, 345; b) V.V. Ovsyankin, in 'Spectroscopy of Solids Containing Rare Earth Ions', Eds. A.A. Kaplyanskii and R.M.MacFarlane, North-Holland, Amsterdam, 1987, p. 343.

[13] L. Zhang, J. Yu, S. Huang, J. Lumin. 1990, 45,301 .

[14] C. Wei, K. Holliday, A.J. Meixner, M. Croci, U.P. Wild, J. Lumin. 1991, 50, 89.

[15] A. Oppenlander, F. Madeore, J.-C. Vial, J.P. Chaminade, J. Lumin. 1991, 50, 1.

[16] H. Bill, University of Geneva, unpublished results, 1972.

[17] D. Nicollin, H. Bill, Solid State Commun. 1976, 20, 135.

[18] D. Nicollin, H. Bill, J. Phys. C: Solid State Phys. 1978, /1, 4803.

[19] a) J. F. Scott, J. Chem. Phys. 1968, 49, 2766. b) M. Mohnhaupt, Ph.D. Thesis, University of Geneva, 1988.

[20] W. Kleemann, F. Fischer, Z. Phys. 1966, $197,75$.

[21] K. Holliday, C. Wei, M. Croci, U.P. Wild, J. Lumin., to be published.

[22] R.A. Sharma, I. Johnson, J. Am. Ceramic Soc. 1969, 52, 612 . 